\title{
LEVANTAMENTO DAS METODOLOGIAS PROPOSTAS PARA VALORAÇÃO ECONÔMICA DE BENS AMBIENTAIS
}

\author{
Gabriel de Magalhães Miranda ${ }^{1}$, Vinicius Vitale ${ }^{2}$, João Fortunato Zampier ${ }^{3}$ \\ ${ }^{1}$ Eng. Florestal, Dr., Depto. de Engenharia Ambiental, UNICENTRO, Irati, PR, Brasil - gmiranda@ irati.unicentro.br \\ ${ }^{2}$ Eng. Florestal, Mestrando em Engenharia Florestal, UNICENTRO, Irati, PR, Brasil - viniflorestal@ hotmail.com \\ ${ }^{3}$ Especialista em Gestão Ambiental, UNICENTRO, Irati, PR, Brasil - fortunatozampier@yahoo.com.br
}

Recebido para publicação: 07/07/2008 - Aceito para publicação: 02/02/2009

\begin{abstract}
Resumo
O presente estudo tem por objetivo mostrar alguns métodos de valoração de bens ambientais. Esses métodos têm a finalidade de auxiliar na estimativa ou atribuição de valor econômico aos recursos ambientais, por meio da simulação de um mercado hipotético, independentemente de existirem ou não preços de mercado relacionados a eles. Não se trata da transformação de um bem ambiental num produto de mercado, mas sim na mensuração das preferências dos indivíduos sobre a alteração no meio ambiente. O presente trabalho visa a avaliar a aplicabilidade dos métodos de valoração para determinar o valor econômico dos bens ou recursos. O desafio presente para todas as correntes de pensamento é compreender suas limitações e buscar avanços na percepção dos fenômenos naturais e econômicos orientados pelo objetivo maior, que é o desenvolvimento sustentável.

Palavras-chave: Bens ambientais; valoração econômica; metodologias.
\end{abstract}

\begin{abstract}
The survey of the methodologies proposed for economical valorization the environmental goods. The present study has the aim to show some methods about the valorization of the environmental goods. These, methods have the purpose to help an estimative or attribution of economic value to the environmental resources, through the simulation of a hypothetic market, independent if there are prices of the market relating to them. It's not about the transformation of environmental good of a product of the market, but the mensuration of the individual preferences about the alteration of the environment. The present work has the aim to evoluate the application of the methods of the valorization to determine the economic value of the goods or resources. The present challenge to all chains of thought is to understand their limits and look for natural and economic phenomenom advantages that bads to a main purpose that is the maintainance development.

Keywords: Environmental goods; economical valorization; methodologies.
\end{abstract}

\section{INTRODUÇÃO}

Em períodos anteriores da nossa história, as sociedades capitalistas não tinham preocupação com os recursos naturais, pois a abundância deles, associada à baixa intensidade de uso, passava a ideia equivocada da impossibilidade de exaustão e de escassez. Com a evolução da indústria e da mecanização da agricultura, que se deu de maneira intensa, sem a visão conservacionista, o meio ambiente sofreu severamente (ASCELRAD ${ }^{1}$ citado em CAVALCANTI, 1995). Sabendo-se que todas as economias dependem do meio ambiente como fonte de sustentação e pelo fato de as políticas ambientais estarem a cada dia mais sofisticadas, existe uma necessidade de maior desenvolvimento das bases econômicas, principalmente, para a valoração monetária desses bens.

A maior dificuldade está na atribuição de valores, já que muitas vezes ela é feita de maneira incerta e subjetiva. Assim, as avaliações de natureza ambiental não se distinguem por sua doutrina, determinando

\footnotetext{
1 ACSELRAD, H. Externalidade ambiental e sociabilidade capitalista. In: CAVALCANTI, C. Desenvolvimento e natureza: estudos para uma sociedade sustentável. São Paulo: Cortez, 1995. p. 128-138.
} 
constante atualização e criatividade, de modo a melhor enfocar os aspectos técnicos mais relevantes, cujo detalhamento exige conhecimento especializado nas mais diversas áreas (CAMARGO, 1995).

Para May; Lustosa (2003) a análise ambiental consiste numa atividade interdisciplinar, que envolve aspectos econômicos e ecológicos para a obtenção do valor dos recursos ambientais como um todo, exigindo cooperação e coordenação entre os grupos envolvidos. Essa necessidade de valoração dos bens ambientais, independentemente da técnica utilizada, visa a garantir recursos naturais para gerações futuras, dentro dos preceitos do desenvolvimento sustentável. Assim, para que haja desenvolvimento sustentável, é preciso que, do ponto de vista econômico, o crescimento seja definido de acordo com a capacidade de suporte dos recursos naturais, e para que isso aconteça, é necessário valorar economicamente o meio ambiente (FERREIRA, 2003). A valoração dos recursos ambientais se deve também aos alertas, feitos por especialistas das mais diversas áreas, sobre a ameaça que a degradação ambiental representa para a vida no planeta. Ao se fazer uma análise da forma de atribuição de valor a qualquer recurso, é imprescindível entender o significado da palavra "valor".

Segundo Ferreira (1986), valor é a importância de determinado bem, estabelecida ou arbitrada de antemão; é o equivalente justo em dinheiro, mercadoria, etc., especialmente de bem que pode ser vendido ou comprado.

Para Marques; Comune (1995), o valor das relações entre a biodiversidade, que forma o valor total do meio ambiente, não pode ser integralmente revelado, por relações mercantis. Muitos dos seus componentes não comercializados no mercado e os preços dos bens econômicos não refletem o verdadeiro valor da totalidade de seus recursos. Nesse contexto, o problema prático da valoração econômica é obter estimativas plausíveis a partir de situações reais, nas quais não existem "mercados aparentes" ou existem "mercados muito imperfeitos".

\section{REVISÃO DE LITERATURA}

\section{Métodos de valoração econômica ambiental}

Métodos Diretos de Valoração

Esses métodos estimam o valor econômico do bem ambiental a partir da própria disposição da população em pagar por bens ambientais. Podem estar diretamente relacionados com os preços de mercado, e são baseados nas relações físicas que descrevem causa e efeito. Eles partem do pressuposto de que a variação da qualidade ou da quantidade do bem ambiental irá afetar os padrões de bem-estar das pessoas. Com base nessa variação de bem-estar, pode-se estimar a disposição das pessoas a pagar para evitar, ou a disposição a receber para aceitar as alterações do ambiente. São possíveis de se aplicar quando uma mudança na qualidade ambiental ou na quantidade de recursos naturais afeta a produção do processo econômico. A maneira de captação da Disposição a Pagar (DAP), direta ou indiretamente sobre as preferências das pessoas, será o determinante para a classificação dos métodos diretos de valoração (MÉRICO, 1996).

\section{Disposição a Pagar (DAP) Direta}

A maior limitação dos métodos de valoração encontra-se na ineficiência da estimação de valores que não se relacionam ao uso dos bens ou recursos ambientais. As pessoas podem sentir satisfação na mera existência de recursos ambientais, como uma praia, rio ou lago, mesmo sem utilizá-los ativamente. Para a estimação econômica desses valores de não uso, acredita-se que um método de DAP direta possa trazer informações significantes, através do questionamento individual dos valores que a população atribui àquele bem ou recurso. A Disposição a Pagar será a estimativa do valor total do bem ambiental para a pessoa, representando tanto os valores de uso como os de existência (MITCHELL; CARSON, 1989).

\section{Método de Avaliação Contingente}

O Método de Avaliação Contingente (MAC) é um método direto de valoração econômica. A ideia básica desse método é que as pessoas têm diferentes graus de preferências ou gostos por diferentes bens. As pessoas são interrogadas sobre suas disposições a pagar (DAP) para evitar/corrigir, ou a receber (DAC) para aceitar alteração na provisão de um bem ambiental, mesmo que nunca o tenha utilizado. Embora criticado, em muitos casos é o único método capaz de captar valores de bens e recursos ambientais, sendo adaptável à maioria dos problemas ambientais. 
Esse método é utilizado para a mensuração de:

a) recursos de propriedade comum ou bens cuja exclusão do consumo não possa ser feita, tais como a qualidade do ar ou da água;

b) recursos de amenidades, tais como características paisagísticas, culturais, ecológicas, históricas ou singularidade; $\mathrm{e}$

c) outras situações em que dados sobre preços de mercado estejam ausentes.

Em resumo, o Método de Avaliação Contingente pode ser dividida em estágios. O primeiro, seria a formação do mercado hipotético ou cenário a ser proposto ao entrevistado. Nesse estágio, prepara-se um questionário descrevendo o recurso ambiental a ser analisado e aplica-se esse questionário em pesquisa piloto. Em seguida, é realizada a pesquisa de campo, com aplicação do questionário ajustado segundo se verificou no teste piloto, para saber das disposições individuais a pagar à vista do que foi exposto. Por fim, avalia-se a disposição a pagar média, a partir de técnicas econométricas, e multiplicando-se pela população-alvo da pesquisa (NOGUEIRA et al, 2000).

\section{Método de Ranqueamento Contingente}

Nesse método, as pessoas participantes do processo recebem vários cartões, cada qual descrevendo uma situação diferente ou alternativas hipotéticas com relação ao bem ambiental e outras características que seriam argumentos na função utilidade do entrevistado. Esses indivíduos organizam seus cartões em ordem de preferência, e os valores relativos aos recursos podem ser inferidos a partir desse ranqueamento contingente, utilizando-se as taxas marginais de substituição entre qualquer das características e o recurso ambiental. Se algum dos outros bens ou características tiver preço de mercado, é possível calcular a disposição do entrevistado a pagar pelo recurso ambiental. Esse método é aplicável em situações em que o cenário hipotético poderia ser pouco compreendido pelos entrevistados. A lógica para sua utilização é que os indivíduos teriam maior facilidade em expressar suas preferências (ORTIZ, 2003).

\section{Disposição a Pagar (DAP) Indireta}

Nesse grupo, os métodos obtêm indiretamente a disposição a pagar das pessoas para bens e recursos ambientais, recorrendo a um mercado de bens complementares. Exemplos: a qualidade da água do mar que determina o número de visitas a uma praia e a poluição sonora que influencia o preço das residências em uma região. Com os dados levantados através de questionários adequados, avalia-se como o comportamento das pessoas em relação a esses bens privados complementares pode trazer as informações necessárias para estudo da demanda pelo bem ou serviço ambiental (MOTTA, 1998). Os métodos indiretos de disposição a pagar mais conhecidos são o de Preços Hedônicos, o de Custo de Viagem e o de Comportamento Preventivo.

\section{Método de Preços Hedônicos}

Esse método estabelece uma relação entre os atributos de um produto e seu preço de mercado, podendo ser aplicado a qualquer tipo de mercadoria, embora seu uso seja mais frequente em preços de propriedades. A teoria econômica reconhece que as características ambientais, tais como qualidade do ar e da água, afetam a produtividade da terra, alterando os benefícios dos produtores e consumidores. Esse raciocínio indica que, ao comprar um imóvel, as pessoas consideram também as características estruturais, como a área construída, o número de cômodos e as características ambientais do local de construção. Também farão parte do modelo econométrico os índices socioeconômicos da região e outras variáveis que possam influenciar o valor do bem (HANLEY; SPACH, 1993). Entretanto, numa situação em que indivíduos não tenham clara percepção sobre o recurso natural estudado, como, por exemplo, a existência de um lençol freático no subsolo de uma região, os preços das propriedades não refletirão a importância desse atributo ambiental, portanto não sendo recomendável o uso dessa metodologia.

\section{Método do Custo de Viagem}

É uma das mais antigas metodologias e é usada na valoração de sítios naturais de visitação pública. O valor do bem ambiental será estimado pelos gastos dos visitantes para se deslocar até o sítio, incluindo transporte, tempo de viagem, taxa de entrada e outros gastos complementares. O método estabelece uma função, relacionando os gastos acima citados e outras variáveis que possam explicar a visita ao sítio natural. Os dados serão obtidos através de questionários aplicados a uma amostra da população no local de visitação. A taxa de visitas pode ser expressa em número de visitas pela população, ou visitas por indivíduo num determinado horizonte de tempo. Nesses estudos, as entrevistas devem respeitar os distintos períodos do ano, como verão e inverno, evitando um possível viés sazonal na amostra. 
A distância do sítio natural e sua taxa de visitação tendem a ser inversamente correlacionadas, ou seja, quanto maior a distância, menor o número de visitas (WILLIS; GARROD, 1989). A função de custo de viagem também é incapaz de captar valores de não uso dos bens ambientais, pois somente aqueles que visitam o sítio natural fazem parte do universo amostral. Essa função assume complemento fraco entre a visita ao sítio e a disposição a pagar pelo recurso ambiental, ou seja, a utilidade do mesmo será nula caso o número esperado de visitas seja zero, ou, ainda, a disposição a pagar do indivíduo será nula caso ele não visite o sítio. Embora o método de custo de viagem seja uma boa forma para estimativa do excedente do consumidor em sítios naturais, sua utilização restringe-se a lugares de visitação pública, aos quais os visitantes tenham de se deslocar para visitar.

\section{Método do Comportamento Preventivo}

O Método do Comportamento Preventivo permite avaliar a qualidade ambiental, tomando como base os gastos feitos para amenizar os efeitos da poluição. Por exemplo, gastos com óculos, protetores solares e outros acessórios para proteção contra os raios ultravioleta. Para a implantação desse método, os indivíduos são informados das mudanças nos seus níveis ambientais e que realizam gastos para sua proteção que correspondem à redução do nível de qualidade ambiental experimentado. A resposta para alguma melhoria ambiental será ajustada aos gastos feitos para se protegerem, de modo a maximizar os benefícios que eles possam obter com uma melhoria. O benefício obtido é a medida da melhoria ambiental (SILVA, 2003).

\section{Métodos Indiretos de Valoração}

Os Métodos Indiretos de Valoração estimam o valor de um bem ambiental indiretamente, por meio de uma função de produção. O objetivo é calcular o impacto de uma alteração do recurso ambiental na atividade econômica, utilizando como referência produtos no mercado que sejam afetados pela modificação na provisão do recurso ambiental. Os métodos indiretos de valoração são divididos em dois outros subgrupos: o método de produtividade marginal e o método de bens substitutos (MÉRICO, 1996).

\section{Método de Produtividade Marginal}

O Método de Produtividade Marginal atribui um valor ao uso da biodiversidade, relacionando a quantidade ou a qualidade de um bem ambiental diretamente com a produção de outro produto com preço definido no mercado. Logo, trata a qualidade ambiental como um fator de produção. O recurso ambiental no processo produtivo será representado por uma função dose-resposta, que relaciona o nível de provisão do recurso ambiental ao nível de produção do produto no mercado. Essa função irá mensurar o impacto no sistema produtivo, dada uma variação marginal na provisão do bem ou serviço ambiental, e a partir dessa variação, estimar o valor econômico de uso do recurso ambiental (MOTTA, 1998).

A construção da função dose-resposta envolve duas etapas básicas. A primeira exige a elaboração de uma função física dos danos, relacionando a dose de poluição ou degradação à resposta do ativo ambiental poluído ou degradado na produção. A segunda corresponde à formulação de um modelo econômico que mensure o impacto financeiro dessas alterações no processo produtivo, porém a função de produção pode ser trivial, caso as relações biológicas e tecnológicas sejam demasiadamente complexas (MOTTA, 1998). A função exigiria a inclusão de múltiplas variáveis e um estudo de campo bem detalhado para conhecimento de todos os agentes que participam do processo.

Mensurar com precisão a provisão de bens ambientais é muito complicado, sendo que maiores dificuldades ainda são encontradas na formação de relacionamentos dose-resposta, que exigem sólidos conhecimentos sobre as ciências naturais (PEARCE, 1993). É muito difícil precisar as relações causais ambientais, pois diversos benefícios tendem a ser afetados pela queda da qualidade ambiental. Para conhecimento dos benefícios ou danos causados, é necessária profunda informação, adquirida por meio de estudos dos processos biológicos, capacidades técnicas e suas interações com as decisões dos produtores e o efeito da produção no bem-estar da população (HANLEY; SPACH, 1993).

$\mathrm{O}$ método de produtividade marginal estima apenas uma parcela dos benefícios ambientais, e os valores tendem a ser subestimados. Os valores de existência, como a preservação das espécies, não fazem parte das estimativas, pois a função de produção capta apenas os valores de uso do recurso ambiental.

\section{Método de Mercado de Bens Substitutos}

Às vezes não é possível obter diretamente o preço de um produto afetado por uma alteração ambiental, mas pode-se compará-lo a algum substituto existente no mercado. A metodologia de mercado de bens substitutos parte do princípio de que a perda de qualidade ou escassez do bem ou serviço ambiental irá aumentar a procura por substitutos, na tentativa de manter o mesmo nível de bem-estar da população. Mas é 
muito difícil encontrarmos na natureza um recurso que substitua outro com a mesma perfeição (VARIAN, 1994). As propriedades ambientais são demasiadamente complexas e suas funções no ambiente pouco conhecidas, para que possam ser substituídas com eficiência. Em geral, as estimativas são subdimensionadas, pois tendem a considerar apenas os valores de uso dos recursos ambientais. Valores de existência, como o da preservação das espécies afetadas pelos danos, não entrarão no cálculo dos benefícios gerados pelo recurso ambiental, pois não fazem parte do mercado. Entretanto, esses métodos fornecem uma boa noção da atual avaliação econômica feita pela sociedade para o recurso ambiental.

\section{Método dos Custos Evitados ou Gastos Defensivos}

Esse método estima o valor de um bem ambiental por meio dos gastos com atividades defensivas substitutas ou complementares, que podem ser consideradas uma aproximação monetária sobre as mudanças desses atributos ambientais. Por exemplo, quando se paga para ter acesso à água encanada ou se compra água mineral em mercados, supõe-se que o valor pago está avaliando todos os possíveis efeitos da água poluída e, indiretamente, valorando a disposição a pagar pela água tratada ou descontaminada. Por definição, um substituto perfeito implica que o decréscimo de uma unidade do produto será acompanhado do acréscimo em uma taxa constante de seu substituto (VARIAN, 1994). As estimativas também tendem a ser subestimadas, pois desconsideram alguns fatores, como a existência de um comportamento altruísta do indivíduo para medir o valor atribuído à vida ou à saúde e à falta de informação sobre os reais benefícios do bem ou serviço ambiental.

\section{Método dos Custos de Reposição}

Nesse método, a estimativa ou a valoração dos benefícios gerados por um recurso ou bem ambiental será calculada pelos gastos necessários para a reposição ou reparação, após ele ser danificado (WILLIS; GARROD, 1989). É o caso do reflorestamento em áreas desmatadas e da fertilização para manutenção da produtividade agrícola em áreas onde o solo foi degradado. Suas estimativas baseiam-se em preços de mercado para reparar o bem danificado, partindo-se do pressuposto de que o recurso ambiental possa ser devidamente recuperado. Uma das desvantagens desse método é que, por maiores que sejam os gastos, os reflorestamentos estão longe de recuperar toda a biodiversidade existente em uma floresta nativa, assim como a fertilização artificial dificilmente conseguirá recuperar a fertilidade do solo, que levou milhões de anos para se constituir. Como nem todas as propriedades do bem ambiental serão repostas, as avaliações tendem a ser subestimadas. Contudo, proporcionam uma aproximação dos prejuízos econômicos causados pela alteração do recurso natural. Um outro aspecto positivo do método dos custos de reposição é que ele é de fácil aplicação, pois necessita de poucos dados e recursos financeiros, por não envolver pesquisas de campo.

\section{Método do Custo de Controle}

Esse método representa os gastos necessários para evitar a variação do bem ambiental e manter a qualidade dos benefícios gerados à população. Um exemplo é a implementação de um sistema de controle de emissão de poluentes por uma indústria para evitar a poluição da atmosfera, e o tratamento de esgoto para evitar a poluição dos rios. Embora o controle da degradação limite o consumo presente do capital natural, esse método mantém um nível sustentável de exploração e aumenta os benefícios da população a longo prazo, dando possibilidades de aproveitamento futuro dos recursos naturais. As situações mais críticas desse método estão relacionadas à estimação dos custos marginais de controle ambiental e dos benefícios gerados pela preservação, pois não há um consenso sobre o nível adequado de sustentabilidade, de modo que as pessoas encontram obstáculos para ajustar os custos aos benefícios marginais e determinar o nível ótimo de provisão do recurso natural. Existe uma série de esforços para incluir o capital natural no sistema de contas nacionais. Quanto maior o estoque de capital natural, maior a capacidade do país para gerar renda no futuro, e a escolha pelo consumo presente representa o quanto a sociedade está abrindo mão de seus ativos naturais para a geração de renda (MOTTA, 1998).

\section{Método dos Custos de Oportunidade}

Embora desejável do ponto de vista social, a preservação implica um custo que deve ser mensurado, para permitir a divisão entre os diversos agentes que usufruem dos benefícios da conservação. Toda conservação traz consigo um custo de oportunidade das atividades econômicas que poderiam estar sendo desenvolvidas na área de proteção. $\mathrm{O}$ custo de oportunidade representa as perdas econômicas da população em virtude das restrições do uso dos bens ou recursos ambientais. $\mathrm{O}$ benefício da conservação seria o valor de uso direto do recurso ambiental, estimado pela receita perdida em virtude do não 
aproveitamento em outras atividades econômicas. Um parque ou reserva florestal com exploração restrita gera um custo de oportunidade da extração madeireira que poderia estar sendo desenvolvida no local. Como afirma Pearce (1993), o método é frequentemente utilizado como medida do dano causado, isso porque, quando o dano já ocorreu, normalmente é possível estimar o custo de restauração do ambiente danificado. Por outro lado, a extração acabaria impedindo outra receita, que seria o custo de oportunidade de atividades sustentáveis, como o turismo e a exploração de ervas naturais. A estimativa da oportunidade de exploração deve sempre considerar uma possível diminuição do capital natural ao longo do tempo, que também é uma oportunidade futura de geração de renda. Danos irreversíveis sobre espécies de plantas e animais acabarão reduzindo, a longo prazo, a renda gerada pela exploração.

\section{RESULTADOS E DISCUSSÃO}

O valor do bem ou recurso ambiental será atribuído por seus atributos. Se estiver relacionado à própria existência do bem, sem qualquer associação ao presente ou futuro, dá indícios do valor de não uso do bem ou recurso ambiental. Os valores de uso podem ser classificados em Valor de Uso Direto, Valor de Uso Indireto e Valor de Opção. Dessa maneira, é comum, na literatura, a desagregação do Valor Econômico do Recurso Ambiental (VERA) em Valor de Uso (VU) e Valor de Não Uso (VNU). O VU representa o valor atribuído pelas pessoas pelo uso propriamente dito dos recursos e serviços ambientais, sendo composto pelo Valor de Uso Direto (VUD) e pelo Valor de Uso Indireto (VUI). O VUD corresponde ao valor atribuído pelo indivíduo, devido à utilização efetiva e atual de um bem ou serviço ambiental, por exemplo, extração, visitação ou alguma outra forma de atividade produtiva ou consumo direto, com relação às florestas. O VUI representa o benefício atual do recurso, derivado de funções ecossistêmicas, como, por exemplo, a proteção do solo, a estabilidade climática e a proteção dos corpos d'água, decorrentes da preservação das florestas.

$\mathrm{O}$ valor de Opção (VO) representa o valor que as pessoas atribuem no presente, para que no futuro os serviços prestados ao meio ambiente possam ser utilizados. Por exemplo, o benefício advindo de fármacos que poderão ser desenvolvidos com base em propriedades medicinais de plantas existentes na floresta, ainda não descobertas. O terceiro componente, o Valor de Existência (VE), caracteriza-se como um Valor de Não Uso, que significa um valor conferido pelas pessoas a certos recursos ambientais, como florestas e animais em extinção, mesmo que não tenham intenção de usá-los ou apreciá-los na atualidade ou no futuro. A atribuição do VE é derivada de uma posição moral, cultural e ética em relação aos direitos de espécies não-humanas ou à preservação de outras riquezas naturais, mesmo que elas não representem uso atual ou futuro para o indivíduo.

A atribuição de valor econômico a recursos ambientais pode ser resumida da seguinte forma:

1. Valor de Uso (VU)

1.1.Valor de Uso Direto (VUD)

Apropriação direta de recursos ambientais, via extração, visitação ou outra atividade de produção ou consumo direto.

1.2.Valor de Uso Indireto (VUI)

Benefícios indiretos gerados pelas funções ecossistêmicas.

1.3. Valor de Opção (VO)

Intenção de consumo direto ou indireto do bem ambiental no futuro.

2. Valor de Não Uso (VNU)

2.1.Valor de Existência (VE)

Valores não associados ao consumo e que se referem a questões morais, culturais, éticas ou altruísticas em relação à existência dos bens ambientais.

Resume-se o Valor Econômico do Recurso Ambiental (VERA) na seguinte expressão:

$$
\mathrm{VERA}=\mathrm{VU}+\mathrm{VNU} \text {, ou seja, VERA }=(\mathrm{VUD}+\mathrm{VUI}+\mathrm{VO})+\mathrm{VE}
$$

\section{CONCLUSÕES}

- A valoração do meio ambiente é um dos aspectos mais críticos de todo o processo de contabilização, devido à dificuldade de quantificação dos benefícios gerados.

- É importante considerar o fato de que os estudos sobre os bens ambientais induzem à consideração a longo prazo, pois dificilmente obtêm-se resultados a curto prazo. 
- Vários são os métodos que podem ser utilizados no processo de valoração econômica dos bens ambientais, e a sua escolha depende especificamente de cada caso.

- A valoração econômica é um fator importante no processo de tomada de decisões das políticas ambientais e de desenvolvimento sustentável.

- A atribuição de valor aos bens ambientais é um importante fator de conscientização da população, na medida em que permite o uso de um sistema de contabilidade ambiental, proporcionando uma visão mais completa e concreta dos bens ambientais.

\section{REFERÊNCIAS}

CAMARGO, J. C. F. Critérios de avaliação. In: SEMINÁRIO DE DIREITO AMBIENTAL IMOBILIÁRIO, 1995, São Paulo. Anais... São Paulo: Centro de Estudos da Procuradoria Geral do Estado de São Paulo, 1995.p. 42-62. (Série Eventos, n. 6).

FERREIRA, A. C. S. Contabilidade ambiental. São Paulo: Atlas, 2003. v. 1.

FERREIRA, A. B de H. Novo dicionário da língua portuguesa. 2 ed. Rio de Janeiro: Nova Fronteira, 1986. $1838 \mathrm{p}$.

HANLEY, N.; SAPCH, C. L. Custo-benefício análise e o ambiente. Hants: Edward Elgar Publicação Limitada, Inglaterra, 1993. 278 p.

MARQUES, J. F.; COMUNE, A. E. A teoria neoclássica e a valoração ambiental. In: ROMERO, A. R.; REYDON, B. P.; LEONARDY, M. L. A. (Orgs.) Economia do meio ambiente: teoria, políticas e a gestão de espaços regionais. 2 ed. Campinas: UNICAMP, 1999. p. 21-42.

MAY, P. H.; LUSTOSA, M. C.; VINHA, V. Economia do meio ambiente - teoria e prática. Rio de Janeiro: Elsevier, 2003.p. 61-78, 135-153, 155-172.

MÉRICO, L. F. K. Introdução à economia ecológica. Blumenau: Editora da FURB, 1996.

MITCHELL, R. C.; CARSON, R. T. Using surveys to value public goods: the contingent valuation method. Washington, D.C. : R/F, 1989.

MOTTA, R. S. Manual para valoração econômica de recursos ambientais. Brasília, DF: Ministério do Meio Ambiente, dos Recursos Hídricos e da Amazônia Legal, 1998.

NOGUEIRA, J. M.; MEDEIROS, M. A.; ARRUDA, F. S. Valoração do meio ambiente; ciência ou empirismo? Cadernos de Ciência e Tecnologia, Brasília, DF, v. 17, n. 2, 2000.

ORTIZ, R. A. Valoração econômica ambiental. In MAY, P.; LUSTOSA, M. C.; VINHA, V. Economia do meio ambiente. Rio de Janeiro. Campus, 2003. p. 81-99.

PEARCE, D. W. Economic values and the natural world. Massachusetts: The Mit, 1993. 129 p.

SILVA, J. R. Métodos de valoração ambiental: uma análise do setor de extração mineral. Disponível em: 〈http://teses.eps.ufcs.br/defesa/pdf/10520.pdf>. Acesso em: 28/06/2003.

VARIAN, H. R. Microeconomia: princípios básicos. 4 ed. Rio de Janeiro: Campus, 1994. 710 p.

WILLIS, K.; GARROD, G. An individual travel cost method of evoluating forest recreation. Journal of Agricultural Economic, Reading, v. 42, n. 1, p. 33-42, 1991. 